Eur. J. Clin. Chem. Clin. Biochem.

Vol. 32, 1994, pp. 773-777

(c) 1994 Walter de Gruyter \& Co.

Berlin · New York

\title{
Transferability of Lipase Titrimetric Assays: Deductions from an Interlaboratory Study
}

By P. Arzoglou', C. Goudoula', P. Tsantili ${ }^{1}, J$. M. Lessinger ${ }^{2}$, G. Férard ${ }^{2}$, V. Mignot ${ }^{2}$, N. Samyn ${ }^{3}$, J. Demeester ${ }^{3}$,

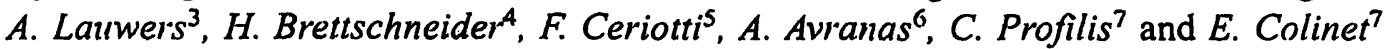

1 Laboratory of Biochemistry, Department of Chemistry, Aristotle University of Thessaloniki, Thessaloniki, Greece

2 Laboratoire de Biochimie Appliquée. Faculté de Pharmacie, Université Louis Pasteur de Strasbourg, Illkirch. France

3 Laboratory of Biochemistry and Physical Pharmacy, School of Pharmacy, Gent, Belgium

${ }^{4}$ Standardization Center, Boehringer-Mannheim, Penzberg, Germany

${ }_{5}^{5}$ Ospedale San Rafaelle, Milano, Italy

6 Laboratory of Physical Chemistry, Department of Chemistry, Aristotle University of Thessaloniki, Thessaloniki. Greece

7 Bureau Communautaire de Référence, BCR, Commission des Communautés Européennes, Bruxelles, Belgium

(Received April 21/July 8, 1994)

Summary: Following the selection of the most appropriate method for emulsification and the optimization of the reaction medium, interlaboratory studies were conducted to check the effect of preparing substrates and measuring the catalytic concentration of lipase at different sites as well as the effect of transport on emulsion. The determinations of lipase activity in an abnormal chemistry control against emulsions prepared by two laboratories (and used by both laboratories) and, also, against five separate emulsions prepared by one laboratory (and used by five different laboratories) resulted in average enzyme activity values (2234 \pm 125 and $2263 \pm 204 \mathrm{U} / \mathrm{l}$ respectively) which are not statistically different. Standard preparations of lipase, control sera and reference materials can therefore be titrated according to the procedure followed by at least two laboratories for at least 3 days against two separate emulsions.

\section{Introduction}

For decades, the unique properties of pancreatic lipase (EC 3.1.1.3) have sustained a controversy over the method and the in vitro conditions for reliable determinations of the enzyme catalytic concentration $(1-4)$. The most widely used routine indirect turbidimetric method (5) requires the prior direct assay of standards and, moreover, is restricted to low substrate concentrations, owing to the limitations of spectrophotometry $(2,4)$. The latest titrimetric assays, which make use of continuousmonitoring $\mathrm{pH}$-stat techniques for direct titration of the released fatty acids, offer a satisfactory approach to the problem, because they allow the use of high substrate concentrations while photometric artefacts are excluded
(6-11). Differences between the assay procedures hitherto described are related to the composition of the reaction mixture (e.g. type and concentration of bile salt) and the type of emulsification procedure employed. Owing to the multitude of emulsification devices, there is a great variation in the physical state of substrates, which in turn affects the expression of lipase activity, thus hindering the comparability of results obtained by different laboratories.

Within the context of this work, an effort was made to deal with some of the main factors involved in the preparation of substrates and to subject the whole titrimetric procedure to an interlaboratory study. 


\section{Materials and Methods}

\section{Apparatus and reagents}

Ultrasonic emulsification was achieved with the Minisonic Homogenizer type 4005 or the Sonifier 250 (Branson Ultrasonics, England). For blending, a Sorvall high-speed blender was used. The temperature of the reaction mixture was maintained constant by thermostated circulating water baths. Lipase activity was determined using a continuous monitoring $\mathrm{pH}$-stat technique. Two laboratories employed Mettler DL-21 automatic titrators (Mettler, Sivitzerland). The other laboratories employed a Mettler DL-25 automatic titrator, a Radiometer TTT-60 automatic titrator and a Radiometer VIT-90 Video titrator (Radiometer, Denmark). The electrodes used were a Mettler DG 112-SC, a Ross combination pH electrode 8102 (Orion, USA), a U-402 (Ingold, Germany), a Radiometer GK-2401B (Radiometer, Denmark) and a Metrohm combined glass electrode 6.02.19.100 designed especially for emulsions (Metrohm, Switzerland). Highly refined olive oil (low acidity), triolein (approximately 95\% pure), bile salts, and the Accutrol $^{\circledR}$ abnormal chemistry controls were purchased from Sigma Fine Chemicals, USA. Hydroxypropyl methylcellulose (cat. No. H: 8384 , viscosity of $2 \%$ aqueous solution at $25^{\circ} \mathrm{C}$ approximately 50 centipoises) was also obtained from Sigma Fine Chemicals. Colipase was provided by Boehringer Mannheim, Germany. Sodium hydroxide ampoules used for the preparation of the titrant and the standard buffers used for the calibration of the electrode were Fixana (Riedel-de Haen, Seelze, Germany). Other chemicals used were analytical grade.

\section{Samples}

Lipase was purified from human pancreatic juice (collected from three patients who developed an extra pancreatic fistula) and stabilized in the presence of albumin (to provide a matrix close to the physiological one) according to a previously described procedure (12). For studies on effectors, lipase was also purified from human pancreatic juice, but stabilized in the presence of low taurodeoxycholate concentrations according to a different procedure (13). Twenty-four plasma samples of patients suffering from acute pancreatitis were also employed to study the correlation of the method with a commonly employed procedure.

\section{Preparation of the emulsion}

Six grams of emulsifier are dissolved in approximately $100 \mathrm{ml}$ of degassed water previously heated to $80-90^{\circ} \mathrm{C}$, by stirring for 15 min. The solution volume is brought to $250 \mathrm{ml}$ with water and stirred for a few more minutes up to the point where a clear, transparent, but still viscous solution is obtained. The solution is transferred quantitatively in a preweighed stoppered bottle and after the addition of $50 \mathrm{~g}$ of olive oil (or the appropriate amount of triolein) the volume is brought to $350 \mathrm{ml}$ with water. After shaking by hand for about $15 \mathrm{~min}$, the distinctly coarse emulsion obtained is further dispersed as follows:

i) Minisonic ${ }^{\circledR}$. Ultrasonic homogenization is achieved by pumping the process materials as a common stream through a specially shaped jet orifice in the homogenizing head. The mixture is irradiated with two bursts (the duration of each one was $30 \mathrm{~s}$ ), with a 1 -min pause period between them to avoid overheating.

ii) Sonifier ${ }^{\circledR}$. Probe sonication was performed three times during $30 \mathrm{~s}$ with 30 -s pauses between them using the maximum capacity of the instrument.

iii) Blender. A minimum volume of $200 \mathrm{ml}$, cooled in ice-water to prevent overheating, was used; two bursts of $5 \mathrm{~min}$ with a 5 -min pause were performed with a medium speed of $11000 \mathrm{~min}^{-1}$.

The concentration of substrate is brought to the desired levels after the addition of the effectors' solutions (deoxycholate, colipase, calcium chloride) before the assay. Best storage conditions for the emulsions are achieved by keeping them in the refrigerator at a temperature between $2-8^{\circ} \mathrm{C}$. When preparing an emulsion volume larger than $350 \mathrm{ml}$, dispersion by sonication or by a blender are achieved on successive $350 \mathrm{ml}$ portions.

\section{Study of physical properties of emulsions}

The particle size distribution of the emulsions was determined with the aid of a Coulter Counter (aperture diameter $=30 \mu \mathrm{m}$ ) allowing measurement of particles with a diameter between 0.6 and $25 \mu \mathrm{m}$. Complete distributions (number-, surface- and volume distribution) were calculated assuming spherical particles (14).

\section{Așsay}

Unless otherwise specified the final concentrations in the reaction mixture per litre were as follows.

Refined olive oil $100 \mathrm{~g}$, sodium deoxycholate $70 \mathrm{mmol}$, colipase $0.2 \mathrm{mg}$, calcium chloride $0.5 \mathrm{mmol}$, hydroxypropyl methylcelluilose

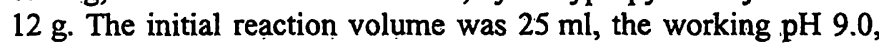
the temperature of the assay $37^{\circ} \mathrm{C}$. Maximal plasma lipase activity is observed over the entire sample volume fraction range from 0.004 to 0.012 . The enzyme activity is calculated as follows:

Lipase catalytic concentration $(\mathrm{U} / \mathrm{l})=\mathrm{A} \times c \times 10^{6} \times \mathrm{V}^{-1}$

where $U$ is defined as $\mu$ moles of fatty acids released per minute; $A$ is the analytical signal ( $\mathrm{ml} \mathrm{NaOH}$ delivered per minute) after deduction of the blank value; $c$ the concentration of the titrant (in our system: sodium hydroxide $5 \mathrm{mmol} / \mathrm{l}$ ) in $\mathrm{mmol} / \mathrm{l}$; $\mathrm{V}$ the sample volume in $\mu \mathrm{l} ; 10^{6}$ converts sample volume to litres.

\section{Transferability studies}

The stability of the sonicated emulsion and the transferability of the whole assay procedure were checked within the bounds of an interlaboratory study carried out in two stages:

- The preliminary trial that included two participating laboratories and

- The final study that was completed with the participation of five laboratories.

Vials of the same lot of Accutrol ${ }^{\circledR}$ containing high lipase activity were used by the participating laboratories.

\section{i) Preliminary trial}

Two separate emulsions were prepared by Laboratory 1 and Laboratory 2 on the same day, following the procedure described (see Materials and Methods). Each laboratory sent by air courier half the portion to the other then measured the lipase activity in triplicate on both its own emulsion and the transported emulsion on prearranged days (day $2,3,4,7$ and 10 following the day of preparation). In this way, transferability was tested within the whole time range (10 days), during which there was shown to be no significant variation of the analytical signal recorded against the same batch of emulsion (see precision data). Both laboratories reconstituted a new vial of Accutrol ${ }^{\circledR}$ daily and used it as the enzyme source. During this study, the influence on results of three conditions was simultaneously checked: 1) the preparation procedure (P) performed in two different sites; 2) the mesaurements (M) with the same emulsion by the two different laboratories; 3) the transport $(\mathrm{T})$ of the emulsion from the site of preparation to the site where 
the measurements took place. The aims of the procedure followed are depicted schematically in figure 1.

\section{ii) Final study}

Five separate emulsions and all the necessary reagents were dispatched from Laboratory 1 to all five laboratories on prearranged days. Each laboratory determined lipase activity in the same lot of Accutrol ${ }^{\circledR}$ on three days of its choice within 10 days from the preparation of the substrate. For every set of determinations the content of a sealed sodium hydroxide ampoule was diluted for the preparation of the titrant, to ensure that any discrepancies observed would not be due to the titration solution.

\section{Results and Discussion}

\section{Comparison between emulsification procedures}

Sonifier ${ }^{\circledR}$ produces emulsions with a low average geometric mean diameter $(2 \mu \mathrm{m}$ on the day of preparation, $2 \mu \mathrm{m}$ after 5 days, and $2.1 \mu \mathrm{m}$ after one week) and good homogeneity; however, using a total volume of $350 \mathrm{ml}$ we observed a decline in emulsifying capacity. The Minisonic $^{\circledR}$ produced droplets with a mean diameter of 2.7 $\mu \mathrm{m}$ (tab. 1); the mean diameter remains practically unchanged during three weeks of storage at $4{ }^{\circ} \mathrm{C}$, and the homogeneity is very satisfactory. The size distribution of oil droplets is depicted in figure 2 . The less homogeneous emulsion was obtained with a high-speed blender: more than $10 \%$ of the droplets have a diameter greater than $10 \mu \mathrm{m}$, but also many droplets have a size below the detection limit of the Coulter $(0.6 \mu \mathrm{m})$. For this reason, only $58 \%$ of the theoretical oil volume is measurable (tab. 1) so the medium diameter for blended emulsions might be even lower than $2.2 \mu \mathrm{m}$. On the

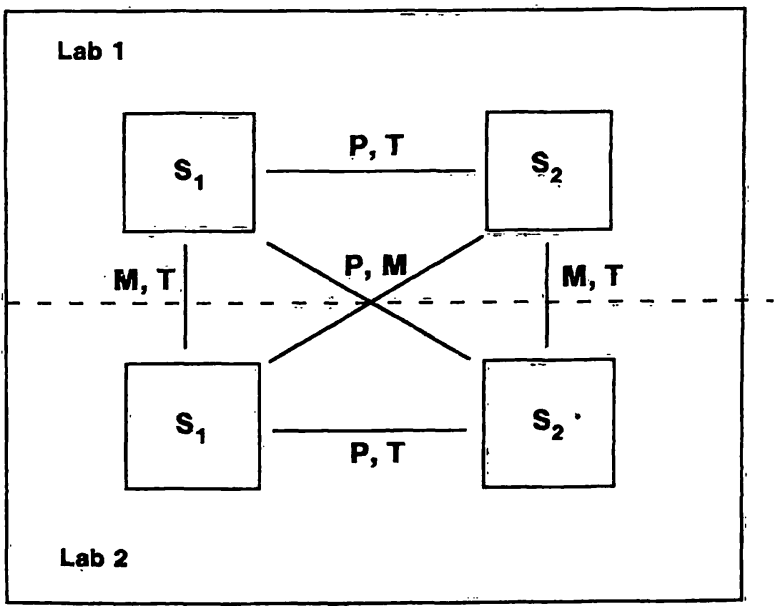

Fig. 1 Scheme for the study of transferability. Laboratories 1 and 2 prepared the emulsions $S_{1}$ and $S_{2}$, respectively. Lipase activity in Accutrol ${ }^{\circledR}$ (same lot) was determined by each laboratory with both emulsions. The possible combinations of the three conditions which may affect the results are indicated as follows: $P=$ preparation (at different sites); $T=$ transport (between sites); $M=$ measurement (at different sites).
Tab. 1 Oil droplets size of emulsions obtained by different procedures.

\begin{tabular}{llll}
\hline Procedure & $\begin{array}{l}\text { Average } \\
\text { diameter* } \\
\mu \mathrm{m}\end{array}$ & $\begin{array}{l}\text { Total } \\
\text { surface-area** } \\
\left(\mathrm{m}^{2} / \mathrm{ml} \text { oil }\right)\end{array}$ & $\begin{array}{l}\% \text { theoretical } \\
\text { oil volume*** }\end{array}$ \\
\hline Sorvall & 2.2 & 1.65 & 58 \\
Sonifier & 2.0 & 2.75 & 95 \\
Minisonic & 2.7 & 2.10 & 88 \\
\hline
\end{tabular}

* Surface-volume diameter, calculated after the determination of both volume and surface by Coulter Counter ${ }^{\circledR}$

** Calculated only from droplets with measurable sizes

*** Relationship between the volume of the oil droplets measured with Coulter Counter and the theoretical oil volume placed in the vessel, taking dilution into account

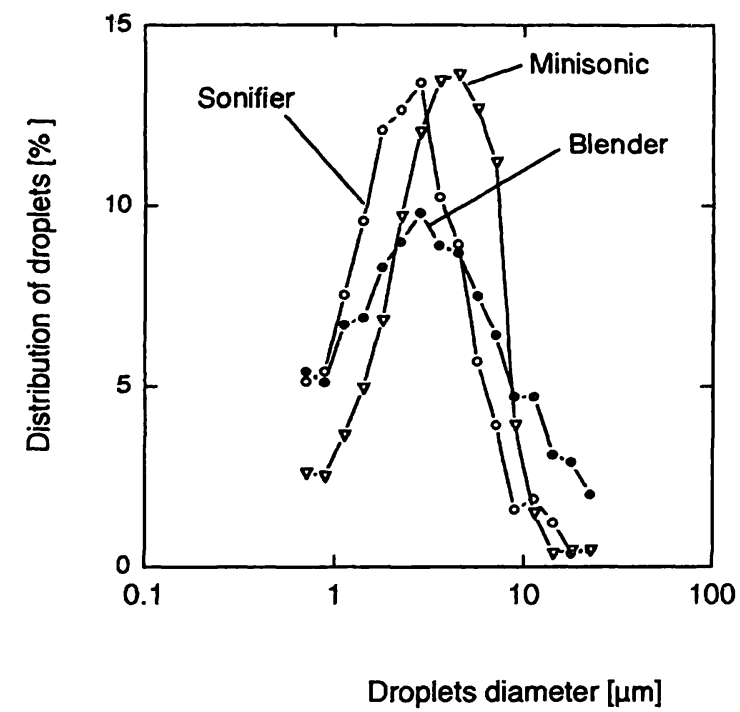

Fig. 2 Oil droplet volume distribution of an olive oil emulsion, after using different procedures of homogenization.

other hand, blended emulsions exhibit an early separation of the two phases after 3 or 4 days of storage at $4{ }^{\circ} \mathrm{C}$, while the sonicated emulsions retained a milky appearance and texture for 10 days; the inclusion of air bubbles in droplets of blended emulsions might also enhance the separation. We therefore performed subsequent assays with emulsions prepared with Minisonic ${ }^{\circledR}$, because they are sufficiently homogeneous and can be obtained at adequate volumes.

\section{Effectors}

Earlier studies showed that the extent of inhibition of purified human lipase activity by $35 \mathrm{mmol} / \mathrm{l}$ of bile salt depends on the type of bile salt used which, in turn, depends on the partition of bile salt molecules between the aqueous and the lipid phase; full inhibition of enzyme activity occurs with $70 \mathrm{mmol} / \mathrm{l}$ of bile salt regardless of the type (13). Other comparative studies led to the conclusion that sodium deoxycholate at $70 \mathrm{mmol} / \mathrm{l}$ 
ensures the highest purified enzyme activity in the presence of $0.1 \mathrm{mg}$ colipase and $0.5 \mathrm{mmol} \mathrm{CaCl}_{2}$ per litre (4). The aforementioned optimal assay conditions were re-confirmed during this study. The influence of colipase concentration on human lipase activity (in the presence of deoxycholate) was studied using different plasma samples (fig. 3). Colipase at $0.2 \mathrm{mg} / \mathrm{l}$ appeared to enhance maximally the enzyme activity in most cases; differences in the degree of activation may be attributed to the presence of various amounts of endogenous colipase in human plasma, as already suggested by Junge et al. (15).

\section{Substrate}

Triolein was also employed at the optimal concentration ( $50 \mathrm{mmol} / \mathrm{l})$, providing about $15 \%$ higher lipase activities, compared with refined olive oil. Although no differences were found for the optimal concentrations of cofactors, triolein is the preferred substrate because its composition is well defined.

\section{Precision and stability data}

A linear response was obtained $(r=0.999)$ after serial dilutions in a $50 \mathrm{mmol} / \mathrm{l}$ Tris/ $\mathrm{HCl}$ buffer $\mathrm{pH} 7.6$ (also containing $40 \mathrm{~g} / \mathrm{l}$ of albumin) of a pancreatic juice sample containing $12400 \mathrm{U}$ per litre. Within-day precision coefficients of variation (CV) are $7.3 \%$ and $2.6 \%$ for samples containing 576 and 1480 units of lipase per litre, respectively $(n=6)$. Values of lipase activity obtained against a certain emulsion within a period of 10 days served to check the stability of the emulsion. A new vial of Accutrol $^{\circledR}$ (same lot) was reconstituted every day and the lipolytic activity was determined using the same emulsion. The mean enzyme activity was $2360 \mathrm{U} / \mathrm{l}$

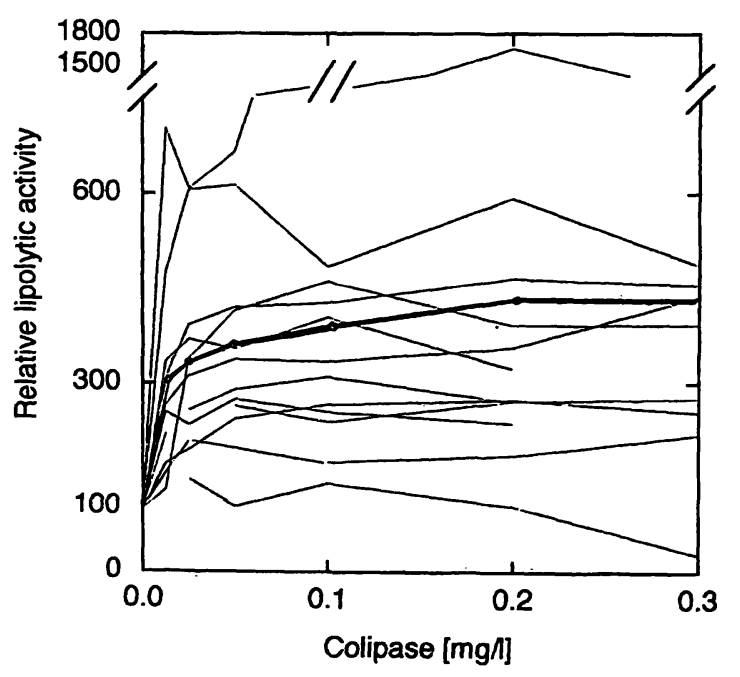

Fig. 3 Plasma lipolytic activities versus various colipase concentrations. Average activation is indicated by the darker line.

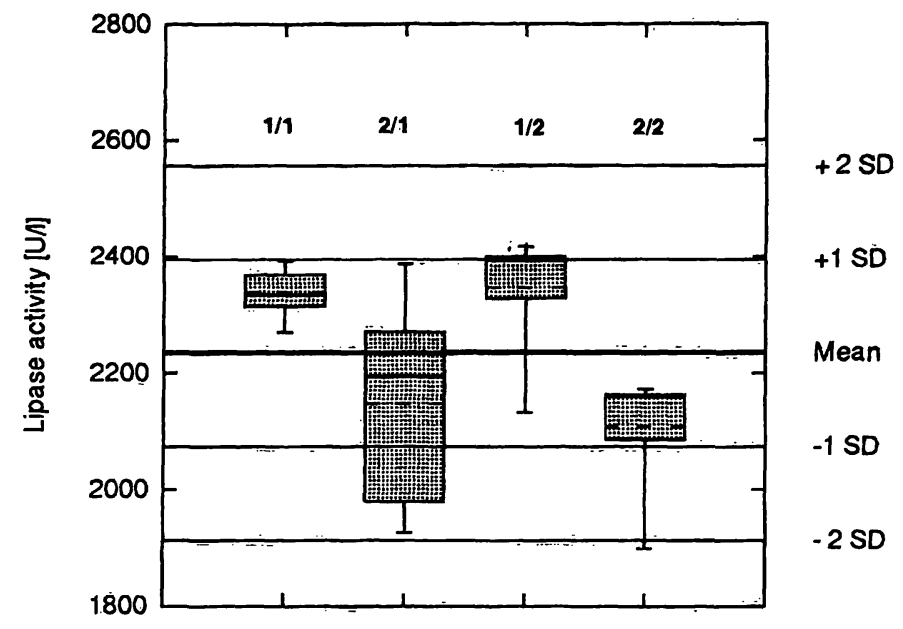

Fig. 4 Statistical evaluation of the results obtained by laboratories 1 and 2 during the preliminary study of transferability. The numbers above the box plots indicate the site of preparation of the emulsion and the site when the measurements took place. Each column of data is graphed as a box indicating the range between the 25 th and 75th percentiles of the data; a line marks the value of the 50th percentile. Capped bars indicate the 5th and 95th percentile points. The extreme data points that lie outside the 5th and 95th percentiles are graphed as symbols. The mean is displayed by a dashed line.

with a CV of 4.8 per cent. Furthermore, plasma lipase activities measured according to the present method $(n=24)$ are closely correlated $(r=0.955)$ with those obtained with a widespread turbidimetric assay (Boehringer-Mannheim, UV-test). The equation is $\mathrm{y}=1.56 \mathrm{x}-$ 81 , where $y$ is the value $(\mathrm{U} / \mathrm{l})$ measured by titrimetry and $x$ the value $(U / 1)$ obtained by turbidimetry.

\section{Transferability of the whole procedure}

The statistical evaluation of the preliminary trial results (fig. 4) shows that the activities determined are close to each other. The mean of means is 2234 units per litre (CV 5.6\%). The means obtained by each laboratory with both emulsions range within the interval "Mean of means \pm one standard deviation". Transport between sites of the sonicated emulsion and measurement in two different sites has no significant influence on the results obtained. The only factor that appeared to be somewhat critical was the preparation of emulsion. This interpretation was confirmed with 5 emulsions (prepared by the same laboratory and with a similar degree of dispersion) during the final interlaboratory study. The mean of all values obtained during the final study of transferability was 2263 units per litre (CV 9\%). Average values determined by the participating laboratories ranged from 2109 to $2615 \mathrm{U} / 1$ with an overall $\mathrm{CV}$ of 8.9 per cent (fig. 5). 


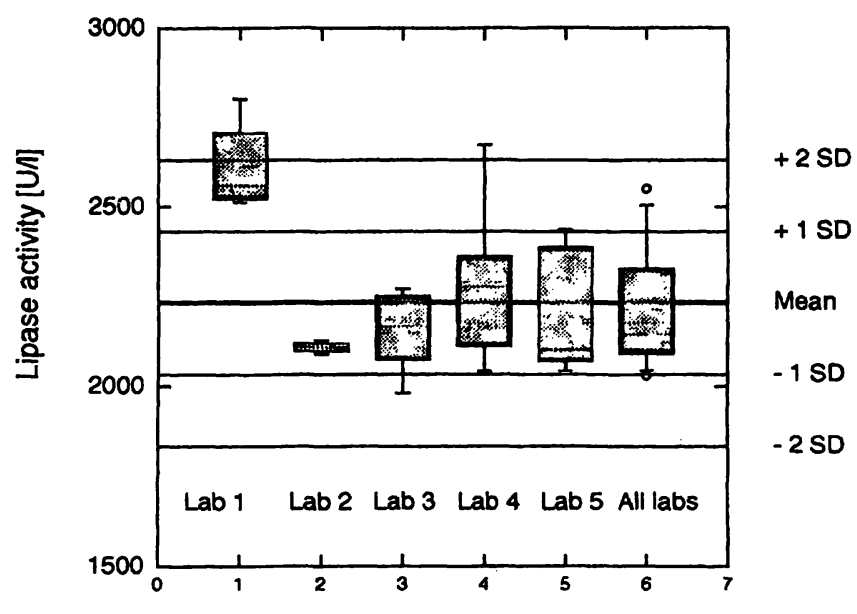

Fig. 5 Statistical evaluation of the results obtained by laboratories $1,2,3,4$, and 5 (random numbers) during the final study of transferability.

\section{Conclusions}

The approach described allowed the assessment of the transferability of the whole titrimetric procedure, including the preparation of substrate. To our knowledge, this has never been previously tested for lipase assays based on "home made" emulsions. Being very time-consum- ing, the whole titrimetric procedure appears to be unsuitable for routine assays. However, the determinations of lipase in Accutrol $^{\circledR}$ against emulsions prepared by two laboratories (during the preliminary trial) and five separate emulsions prepared by one laboratory (during the final study of transferability) resulted in average enzyme activity values $(2234 \pm 125$ and $2263 \pm 204 \mathrm{U} / 1$ respectively) which are not statistically different. Standard preparations of lipase, control sera and reference materials can therefore be titrated following the procedure described by at least two laboratories for at least 3 days against two separate emulsions. In this case, trioleinbased emulsions are preferred, since this type of substrate is relatively pure and well defined. We conclude that, under controlled conditions, the results obtained by titrimetric assays are transferable. This may be of help in the harmonization of results of routine assays by the determination of lipase activity in standards and reference materials.

\section{Acknowledgement}

The present work was funded by the Community Reference Bureau (BCR, European Union, Brussels).

\section{References}

1. Lorentz, K. \& Weiss, T. (1981) Pankreaslipase - Eine Übersicht. Med. Lab. 34, 272-275.

2. Férard, G. \& Lessinger, J. M. (1992) L'activité de la lipase pancréatique humaine: Revue des méthodes et recommandations générales. Ann. Biol. Clin. 50, 133-141.

3. Tietz, N. W. \& Shuey, D. F. (1993) Lipase in serum - The elusive enzyme: An overview. Clin. Chem. 39, 746-756.

4. Arzoglou, P. (1994) La mesure titrimétrique de la concentration catalytique de la lipase pancréatique: État de l'art. Ann. Biol. Clin. 52, 165-170.

5. Hoffmann, G. E. \& Weiss, L. (1980) Specific serum pancreatic lipase determination with use of purified colipase. Clin. Chem. 26, 1732-1735.

6. Tietz, N. W. \& Fiereck, E. A. (1972) Measurement of lipase activity in serum. Stand. Methods Clin. Chem. 7, 19-31.

7. Rick, W. (1969) Kinetischer Test żur Bestimmung der Serumlipasereaktivität. Z. Klin. Chem. Klin. Biochem. 7, 530-539.

8. Tietz, N. W., Astles, J. R. \& Shuey, D. F. (1989) Lipase activity measured in serum by a continuous-monitoring pH-stat technique - An update. Clin. Chem. 35, 1688-1693.

9. Hockeborn, M. \& Rick, W. (1982) Zur Bestimmung der katalytischen Aktivität der Lipase mit dem kontinuierlichen titrimetrischen Test. J. Clin. Chem. Clin. Biochem. 20, 773-785.

10. Tietz, N. W. \& Repique, E. V. (1973) Proposed standard method for measuring lipase activity in serum by a continuous sampling technique. Clin. Chem. 19, 1268-1275.
11. Junge, W. (1984) Pancreatic lipase, titrimetric method. In: Methods of Enzymatic Analysis (Bergmeyer, H. U., ed.) Vol. IV, pp. 15-25, Weinheim, Verlag Chemie.

12. Lessinger, J. M., Tavridou, A., Arzoglou, P. \& Férard, G. (1992) Interest of using a purified, stable and commutable preparation of human pancreatic lipase in indirect assays. Anal. Lett. 25, 1453-1468.

13. Tavridou, A., Avranas, A. \& Arzoglou, P. (1992) A mathematical approach to lipolysis based on the interrelationship of physicochemical and biochemical data. Biochem. Biophys. Res. Comm. 186, 746-752.

14. Demeester, J. \& Lauwers, A. (1987) Computer assisted evaluation of the quality of biological drug samples. Proceedings of the 7th Congress on Medical Informations, Roma 1543.

15. Junge, W., Leybold, K. \& Kraack, B. (1983) Influence of colipase on the turbidimetric determination of pancreatic lipase catalytic activity. J. Clin. Chem. Clin. Biochem. 21, 445-451.

\author{
P. Arzoglou \\ Laboratory of Biochemistry \\ Department of Chemistry \\ Aristotle University of Thessaloniki \\ 54006 Thessaloniki \\ Greece
}


, 